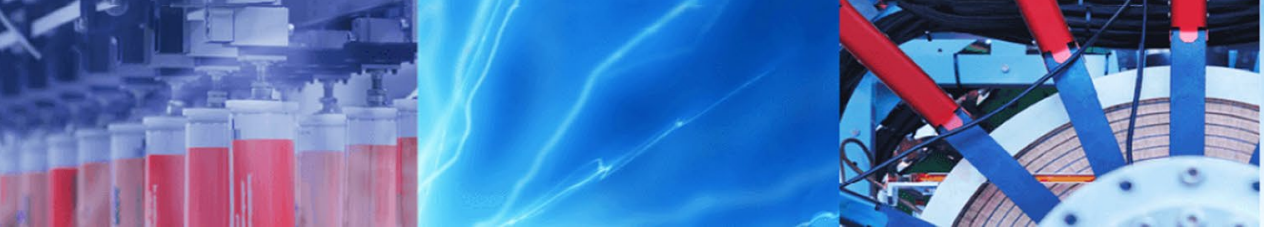

Research Article

\title{
Performance analysis of solar PV based DC optimizer distributed system with simplified MPPT method
}

\author{
J. Ganesh Moorthy ${ }^{1} \cdot$ Sumit Manual $^{1} \cdot$ S. Moorthi ${ }^{1}$ (D) $\cdot$ P. Raja ${ }^{1}$
}

Received: 19 November 2019 / Accepted: 8 January 2020 / Published online: 16 January 2020

(c) Springer Nature Switzerland AG 2020

\begin{abstract}
The proposed work focuses on the design and development of solar photovoltaic (PV) based DC optimizer distributed the system to enable individual maximum power point tracking (MPPT) in solar panels. This DC optimizer distributed system avoids mismatch losses and hot spots in solar PV panels during partial shadow conditions. A novel PI controller based fractional open circuit voltage MPPT method to extract the maximum power has been designed and discussed in this work. The entire system has been designed and modeled in MATLAB/Simulink and the same has been validated in hardware experimentation under varying environmental conditions. The results prove that the proposed system has fast voltage and current settling time with minimum oscillation and is cost-effective as it uses only a voltage sensor eliminating the use of the current sensor.
\end{abstract}

Keywords Solar PV grid-connected system · DC optimizer · MPPT

\section{Introduction}

Nowadays, solar power is one of the most significant energy sources among all renewable sources due to the elimination of greenhouse gas emissions effect, avoid usage of fossil fuels and high accessibility of solar irradiation [1]. However, the environmental conditions such as solar-irradiation and temperature highly impact on the power generation efficiency in the solar PV systems [2]. To improve the power generation efficiency in solar-PV power plants nowadays the research focuses on MPPT and new topology of power converters [3]. Solar PV power plants are conventionally configured central inverter and string inverters [4]. In general, the solar photovoltaic based largescale energy system the solar PV panels are regularly associated in arrangement of series and parallel combinations, in the event that shadow falls on the specific solar PV panel which causes the bungled I-V characteristics, a hot spot in shadow panel and decrease in maximum power point
[5]. The causes of partial shading are clouds, buildings and, trees, dirt accumulation. Due to partial shading, the multiple peaks happen in the series-connected module since it reduces the converter efficiency [6]. To avoid the mismatch losses in the large-scale solar PV energy system bypass diode utilized in parallel with each submodule. Subsequently, bypass diodes are solved the mismatch losses in solar panels to some extent and prevent PV hot spotting. Nevertheless, PV modules incapable of function at their individual MPP [7]. To fathom the above-mentioned drawbacks like mismatch losses, end of bypass diodes and panel-level MPPT this paper focuses on power optimizer topology.

The Power optimizer is a DC/DC converter integrated with each solar-PV modules, that tries to capture MPPT and reduce losses [8] [9]. The PV-battery series inverter architecture proposed in [10] used for the partial-power processing universal dc-dc optimizer to have flexible battery current control and extended PV MPPT control range.

S. Moorthi, srimoorthi@nitt.edu | ${ }^{1}$ Hybrid Electrical Systems Laboratory, Department of Electrical and Electronics Engineering, National Institute of Technology, Tiruchirappalli, Tiruchirappalli, India. 
A dc optimizer modeled in [11] with DC-DC isolated boost converter. A step-down partial power optimizer structure proposed in [12] for PV series-connected optimizer system. DC Power Optimizer for PV Modules Using SEPIC Converter proposed in [8].

The authors [13] have been proposed the DC- optimizer distributed system in large scale grid-connected sun powered PV plants further this system allows better data gathering and protection of power sources.

In order to maximize the energy in solar PV based power plant the Maximum power point tracking is employed. The MPPT is classified into three groups (1) direct method ( $\mathrm{P} \& \mathrm{O}$, incremental conduction) (2) indirect method (Fractional short circuit current, open-circuit voltage) (3) self-computing method [14]. The Perturb and observation $(\mathrm{P} \& \mathrm{O})$ algorithm proposed in [15] to achieve maximum power point form the solar PV panel. To implement this MPPT scheme requires two sensors which sense the voltage and current when a rapid change in irradiation causes the oscillation in MPPT. As compared to the P\&O method, the incremental conductance method is accurate and less oscillation, but the computation complexity is high in [16]. The authors of [17] and [18] has been proposed the fractional open circuit and short circuit methods. To implement both algorithms is very simple, and it delivered a moderate level of accuracy. The multiple peaks in the PV curve cause the power losses the conventional MPPT techniques are wrongly identified local peak as global. To capture global MPPT a tracking loop based on a fuzzy logic controller (FLC) with scanning and storing algorithms used [19]. The paper [20] has been proposed DC optimizer system implemented based on incremental conductance method MPPT method which gives $95 \%$ efficiency to get MPP power voltage and current sensors are required. SEPIC converter-based DC-DC converter is used in DC optimizer type PV distributed system proposed in [8] Further, in this system PI controller is produced PWM pulses to operate SEPIC converter corresponding to measure radiation and temperature sensors.

The uniqueness of the work is to design and development a DC optimizer distributed system, for grid-connected, single-phase solar PV systems. Further, to obtain MPPT for various environmental conditions efficient and simplified MPPT scheme has been proposed to suit the grid-connected application. Whereas in the conventional fractional open circuit voltage (FOCV) algorithm a single $\mathrm{PI}$ control is added for improvement in the MPPT scheme. To implement this algorithm (PI-FOCV) only voltage sensor information is enough. Hence, the current sensor has been eliminated due to this the overall power plant cost reduced. In this paper, the overall proposed system has been designed for $240 \mathrm{Wp}$ capacity and the same has been modeled in MATLAB/Simulink and experimentally.

\section{Proposed DC optimizer distributed system with PI FOCV algorithm}

Figure 1 depicts the $240 \mathrm{Wp}$ capacity DC optimizer distributed system which contains three individual $80 \mathrm{Wp}$ capacity of solar PV panels and it's connected separately with DC-DC converter which is followed by a single-phase inverter. The DC optimizer distributed system operates at "converter per-module" logic. It means that individual DC-DC boost-converters integrated with each solar PV panel and the same has been arranged in series connection. Whereas boost converter is used to boost the individual converter output voltage though the PI-FOCV MPPT method according to their environmental conditions. The power injected to the grid is controlling the duty cycle of a $20 \mathrm{kHz}$ operated MOSFET power switches for each $D C-D C$ converter according to the performance of the PI-FOCV algorithm. The output of the series-connected DC-DC boost converter fed to the single-phase inverter. Moreover, the single-phase inverter injected current with zero harmonics using the PQ controller. This DC optimizer approach offers many advantages such as individual module MPPT, protection of PV sources, elimination of bypass diode and hot spot in shadow panel. Moreover, this design gives flexibility in module layout, in case of source or converter failure happens, replacement and maintenance are easy dc optimize topology.

\subsection{Design and fabrication details of boost-converter}

The basic boost DC-DC converter shown in Fig. 2 is designed for the considered rated and the same has been fabricated for testing. The following specification has been taken for the design of discrete elements in the circuit.

Whereas $V_{S}$ is the dc voltage, $L$ represents inductor, $D$ is a power diode, $C$ represents the capacitor, $S$ denoted as MOSFET switch the capacitor and $V_{0}$ is the voltage output across the resistive load, $R$.

In this scheme, Boost Converter is operated as in DCM mode and the design equations are as follows.

The relation between the output voltage and the input voltage is given by:

$V_{o}=\frac{V_{S}}{1-D}$

Output peak-peak ripple in load current is:

$\Delta i_{L}=\frac{V_{S} D T}{L}$

Output peak-peak ripple in load voltage is: 


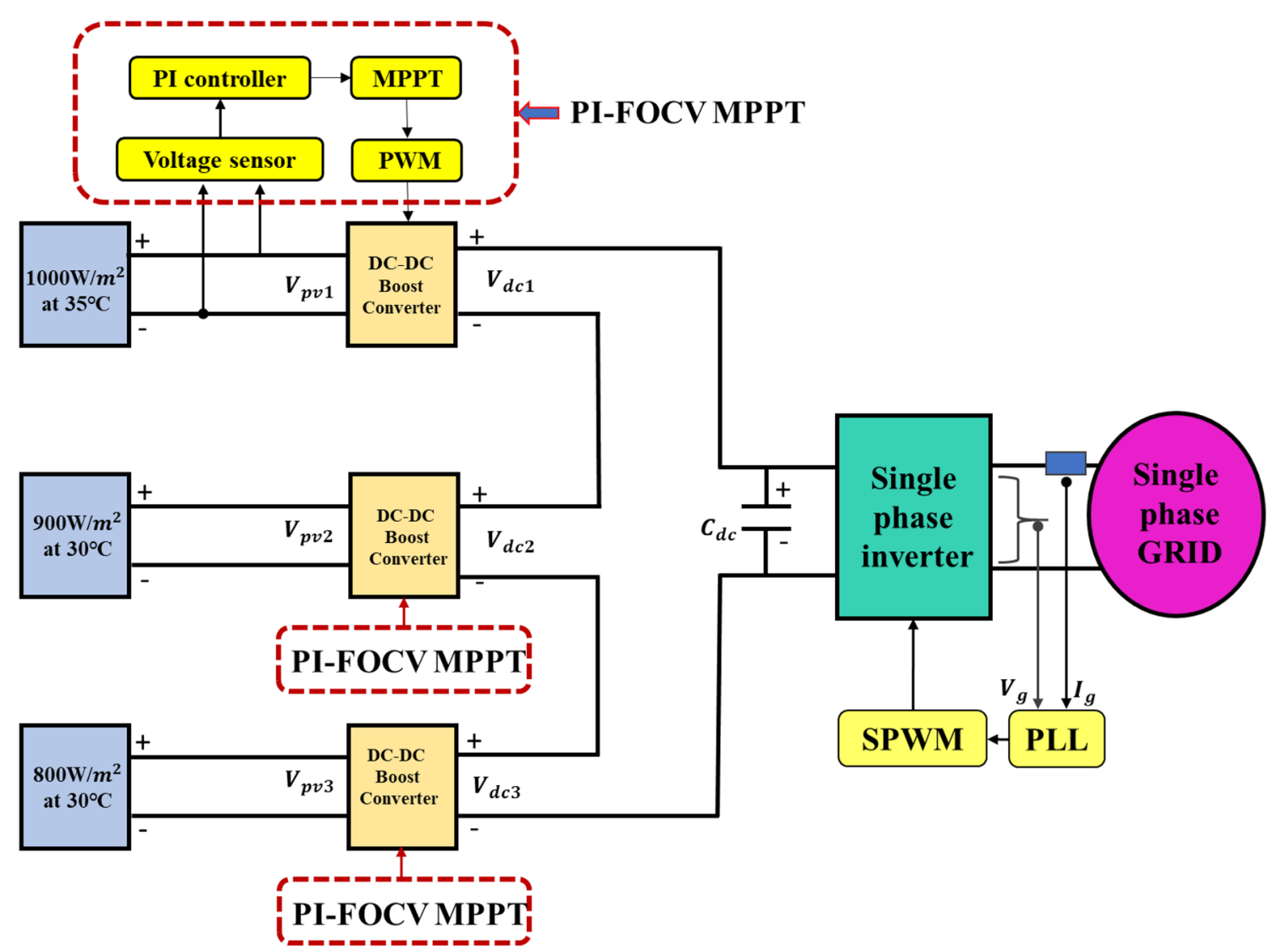

Fig. 1 Block diagram of the proposed DC Optimizer system and MPPT control

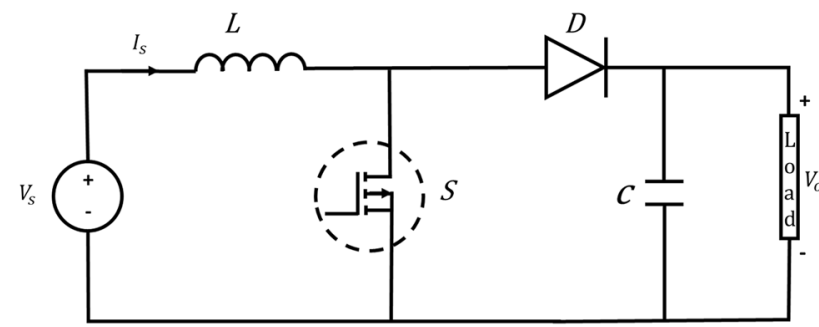

Fig. 2 Boost-converter

$\Delta V_{o}=\frac{V_{o} D}{R C f}$

Taking the Table 1 parameter, switching frequency $f_{s}=20 \mathrm{kHz}$ considering ripple voltage and current with a stable operation the values of $L$ and $C$ are obtained as $10 \mathrm{mH}$ and $470 \mu \mathrm{F}$ respectively. The power switch MOSFET IRFP250N of the Boost Converter has been fabricated with a heat sink which is rated for $V_{D S S}=200 \mathrm{~V}$, $R_{D S(\text { on) }}=0.075 \Omega, I_{D}=30$ A one capacitor of $470 \mu F / 450 \mathrm{~V}$ and one inductor of $10 \mathrm{mH} / 10 \mathrm{~A}, 20 \mathrm{kHz}$ frequency, and one diode $1 \mathrm{~N} 5408,3 \mathrm{~A}$. The MOSFET is provided with a
Table 1 Solar-PV panel specifications

\begin{tabular}{lll}
\hline Parameter & Symbol & Actual values \\
\hline Open circuit voltage & $\mathrm{V}_{\mathrm{oc}}$ & $21.8 \mathrm{~V}$ \\
Short circuit current & $\mathrm{I}_{\mathrm{sc}}$ & $4.98 \mathrm{~A}$ \\
Maximum voltage & $\mathrm{V}_{\mathrm{m}}$ & $17.5 \mathrm{~V}$ \\
Maximum current & $\mathrm{I}_{\mathrm{m}}$ & $4.58 \mathrm{~A}$ \\
Maximum power & $\mathrm{P}_{\mathrm{m}}$ & $80 \mathrm{Wp}$ \\
Series resistance & $\mathrm{R}_{\mathrm{s}}$ & $0.2372 \Omega$ \\
Shunt resistance & $\mathrm{R}_{\mathrm{sh}}$ & $224.18 \Omega$ \\
Diode quality factor & $\mathrm{a}$ & 1.019 \\
\hline
\end{tabular}

heat sink. The firing pulses to the MOSFET are generated using the ARDUINO UNO controller.

\section{PI-FOCV MPPT technique}

In the conventional Fractional Open Circuit Voltage (FOCV) algorithm, in order to achieve solar PV panel maximum voltage $V_{m p}$, the operating point of solar PV voltage set to 0.7 or 0.8 times of open-circuit voltage $V_{\text {oc }}$. It results in shifting of solar PV power towards at $\mathrm{P}_{\mathrm{mp}}$. In this paper to improve the 
conventional FOCV method, a single PI controller is added. $\mathrm{PI}$ controller comprising of a pole and a zero. Moreover, it can be effectively executed either utilizing op-amps or using digital controllers. The transfer function of the PI controller is given by

$$
C(s)=K_{p}+\frac{K_{l}}{s}
$$

The Proportional segment of the PI controller has an effect on the transient response whereas an integral segment impacts the steady-state response. Further, the transfer function of the proposed system has been derived to tune the PI controller gains value using the Ziegler Nichols tuning strategy in which $\mathrm{Kp}$ value has been considered very small compared to Ki value for maintaining a system as stable with minimizing errors. Also, this tuning technique doesn't require entire knowledge about the overall plant transfer function.

In this algorithm initially, real-time solar panel voltage is detected by a voltage sensor. Further, real-time solar PV voltage is compared with set voltage $\left(\mathrm{V}_{\mathrm{mp}}\right)$. Hence, a gotten blunder from the comparator is bolstered to the PI controller and the same error has processed. To find the present duty value named $(k)$ the processed error signal $\left(V_{p}\right)$ processed by the $\mathrm{PI}$ controller is subtracted from the previous duty cycle value after scaling $\left(V_{e}\right)$ suitably. Finally, the pulse of duty $d(k)$ is then fed to the power switch to obtain MPPT under certain environmental conditions.

\section{Results and discussions}

The overall DC optimizer block diagram as shown in Fig. 1 has been modeled in MATLAB/Simulink to validate the performance of MPP for the PI-based FOCV algorithm. As shown in Fig. 3, three solar-PV panels of $80 \mathrm{Wp}$ are connected individually to a DC-DC converter, followed by boost converters which are series in connection to single-phase inverter. Three solar PV-panels are tested for the different irradiations and temperature changes such as irradiation of $1000 \mathrm{~W} / \mathrm{m}^{2}$, $900 \mathrm{~W} / \mathrm{m}^{2}$ and $800 \mathrm{~W} / \mathrm{m}^{2}$ and temperatures of $35^{\circ} \mathrm{C}, 30^{\circ} \mathrm{C}$ and $30^{\circ} \mathrm{C}$ respectively used to validate both numerical simulations and real-time experimentations results. The solar panel specifications and boost converter parameter details are tabulated in Tables 1 and 2 to evaluate the proposed controller's performance analysis using developed hardware set-ups and computer programs.

\subsection{Simulation studies}

Figures $4 a-c$ are depicting the operating point at which maximum power tested for different environmental conditions in sequential order of irradiations and temperatures

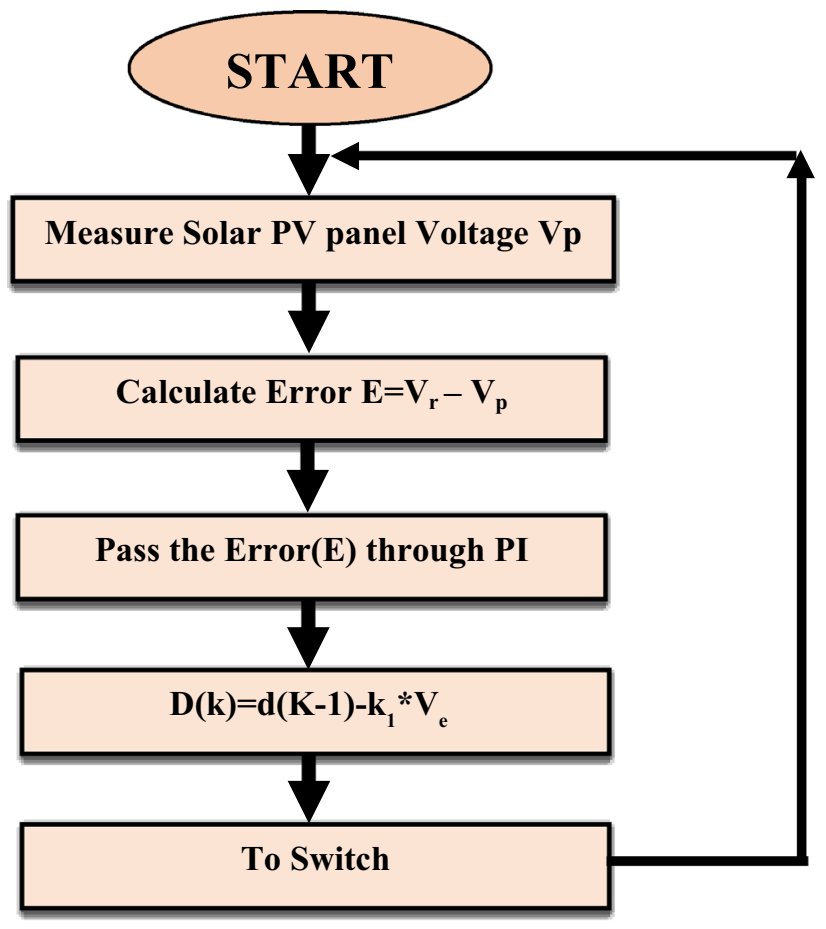

Fig. 3 Flowchart for PI-FOCV Algorithm

Table 2 Boost converter parameters

\begin{tabular}{lll}
\hline Parameter & Symbol & $\begin{array}{l}\text { Actual } \\
\text { value in SI } \\
\text { units }\end{array}$ \\
\hline Switching Frequency & $\mathrm{fs}$ & $20 \mathrm{kHz}$ \\
Input Capacitance & $\mathrm{C}_{\text {in }}$ & $1.5 \mu \mathrm{F}$ \\
Inductance & $\mathrm{L}$ & $10 \mathrm{mH}$ \\
Filter Capacitance & $\mathrm{C}_{\mathrm{f}}$ & $450 \mu \mathrm{F}$ \\
\hline
\end{tabular}

as follows, $1000 \mathrm{~W} / \mathrm{m}^{2}$ at $35{ }^{\circ} \mathrm{C}, 900 \mathrm{~W} / \mathrm{m}^{2}$ at $30^{\circ} \mathrm{C}$ and $800 \mathrm{~W} / \mathrm{m}^{2}$ at $30^{\circ} \mathrm{C}$ respectively. It is observed from the Fig. 1, the proposed PI controller based FOCV algorithms has perfectly extracting maximum power for individual panels with the help voltage sensors only for the different environmental conditions. Also extracted maximum power from these individual solar panels has been together to avoid mismatch loss, hotspot created string inverter and central inverters based solar PV power plants to deliver power into the grid-tied with single-phase inverter.

From Fig. 5, the voltage, current and power waveforms of solar PV panel- 1 of $80 \mathrm{Wp}$ which is operated at irradiation of $1000 \mathrm{~W} / \mathrm{m}^{2}$ and temperature at $35^{\circ} \mathrm{C}$. The simulation results show that the settling time of voltage and current is very less. The convergence of MPP takes $0.02 \mathrm{~s}$ even without the current sensor which improves the overall DC optimizer efficiency. 

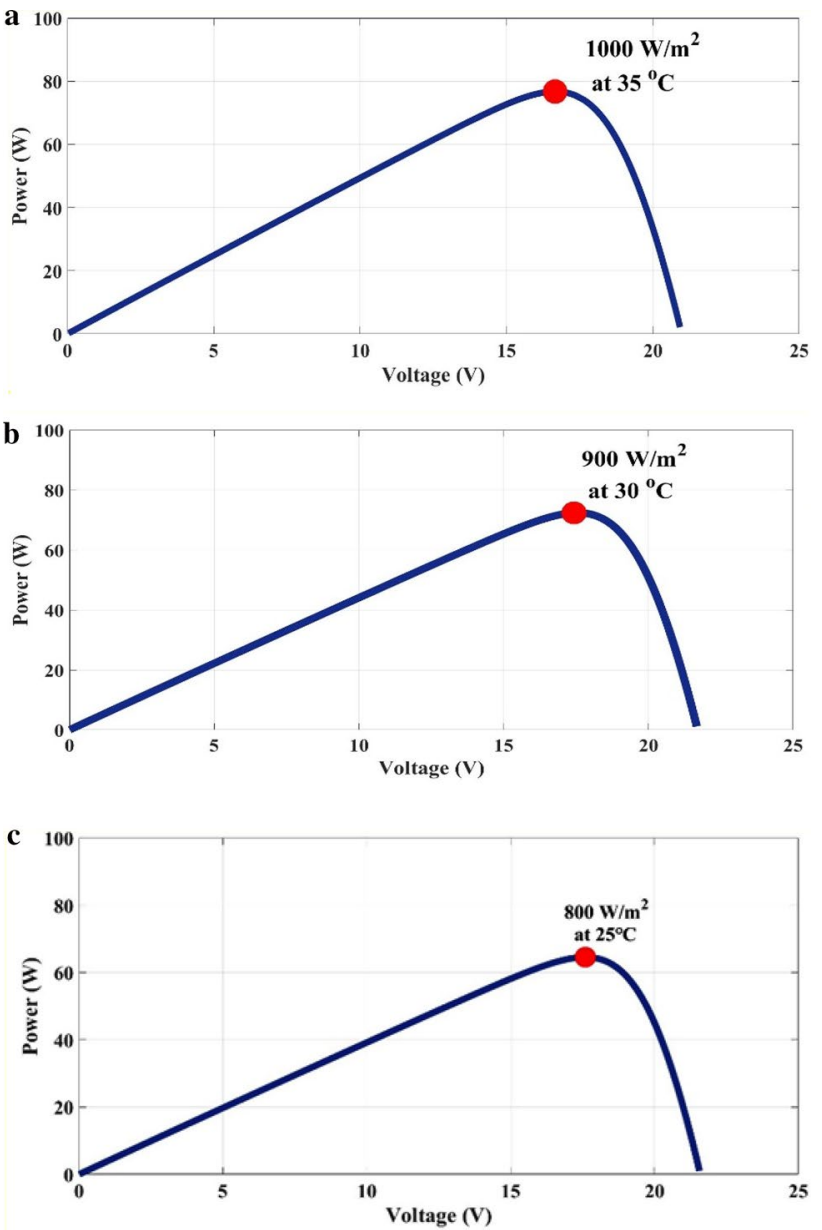

Fig. 4 a Solar PV curve under standard condition. b Solar PV curve for $900 \mathrm{~W} / \mathrm{m}^{2}$ irradiation at $30^{\circ} \mathrm{C}$. c Solar PV curve for $800 \mathrm{~W} / \mathrm{m}^{2}$ irradiation at $30^{\circ} \mathrm{C}$
Table 3 depicts individual solar PV panels value of $\mathrm{V}_{\mathrm{mp}}$ $\mathrm{I}_{\mathrm{mp}}, \mathrm{P}_{\mathrm{mp}}, \mathrm{V}_{\mathrm{DC}}$, and $\mathrm{I}_{\mathrm{DC}}$. Whereas output dc optimizer voltage is $83.81 \mathrm{~V}$ and output RMS current is $2.328 \mathrm{~A}$ output power calculated is $195.24 \mathrm{~W}$ sum of the output power of Panels is $201.46 \mathrm{~W}$. Hence, the total losses calculated as $6.22 \mathrm{~W}$, which is low as compared to conventional topologies.

The grid voltage and injected current with respect to time have been reported in Fig. 6, which shows that grid voltage is in phase with the grid current which enables the DC optimizer to transfer maximum power to the gird. Moreover, the shape of the injected current is sinusoidal and zero reactive power delivered to the grid which ensures the inverter system is the stable and optimal design for carrying out experimental verification.

\subsection{Experimental studies}

Figure 7 depicts the hardware implementation model of DC optimizer. The three individual Boost converter has been tested experimentally using a solar simulator and solar PV panels with a closed-loop control method. The closed-loop control and PI-FOCV MPPT technique are implemented using the Arduino UNO microcontroller. The input $D C$ voltage is changed in accordance with the change in irradiation as taken from the practical PV curve. With the help of Arduino Uno, the duty ratio based on the voltage sensor has been automatically adjusted. To provide the power supply to controller and gate driver circuit a 230/5 V single-phase step-down transformer has been used. As shown in Fig. 8 the LM317PSU used as an adjustable voltage regulator circuit which converts the stepdown $A C$ voltage to the required $D C$ voltage supply for the gate driver circuit.
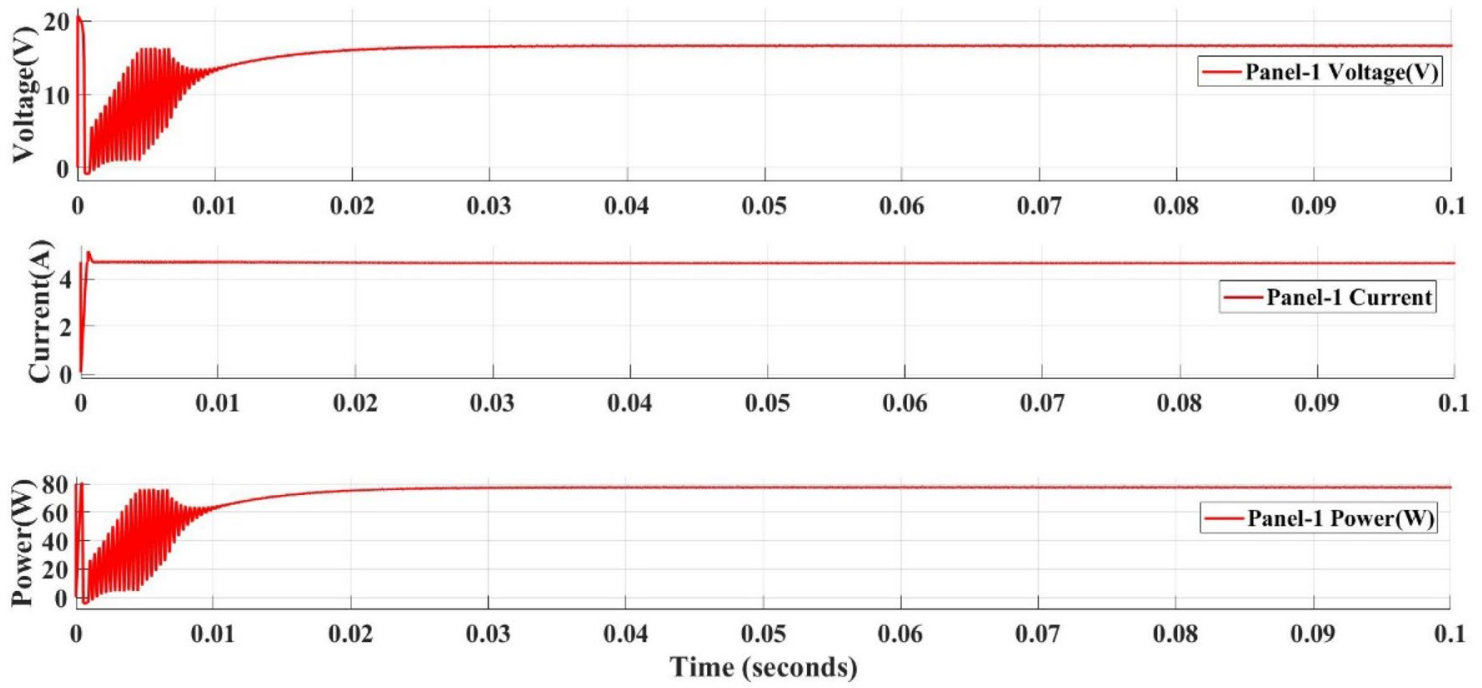

Fig. 5 Voltage, current waveforms at irradiation of $1000 \mathrm{~W} / \mathrm{m}^{2}$ temperature of $35^{\circ} \mathrm{C}$ 
Table 3 Individual solar PV panels value of $\mathrm{V}_{\mathrm{mp}}, \mathrm{I}_{\mathrm{mp}}, \mathrm{V}_{\mathrm{DC}}$ and $I_{D C}$

\begin{tabular}{llllllll}
\hline $\begin{array}{l}\text { Solar PV } \\
\text { panel }\end{array}$ & $\begin{array}{l}\text { Radiation } \\
\left(\mathrm{W} / \mathrm{m}^{2}\right)\end{array}$ & Temp $\left({ }^{\circ} \mathrm{C}\right)$ & $\mathrm{V}_{\mathrm{mp}}(\mathrm{V})$ & $\mathrm{I}_{\mathrm{mp}}(\mathrm{A})$ & $\mathrm{P}_{\mathrm{mp}}(\mathrm{A})$ & $\mathrm{V}_{\mathrm{DC}}(\mathrm{V})$ & $\mathrm{I}_{\mathrm{DC}}(\mathrm{A})$ \\
\hline 1 & 1000 & 35 & 16.52 & 4.566 & 78.99 & 32.39 & 2.36 \\
2 & 900 & 30 & 16.77 & 3.856 & 65.02 & 27.24 & 2.34 \\
3 & 800 & 30 & 17.2 & 3.338 & 57.45 & 24.18 & 2.32 \\
\hline
\end{tabular}

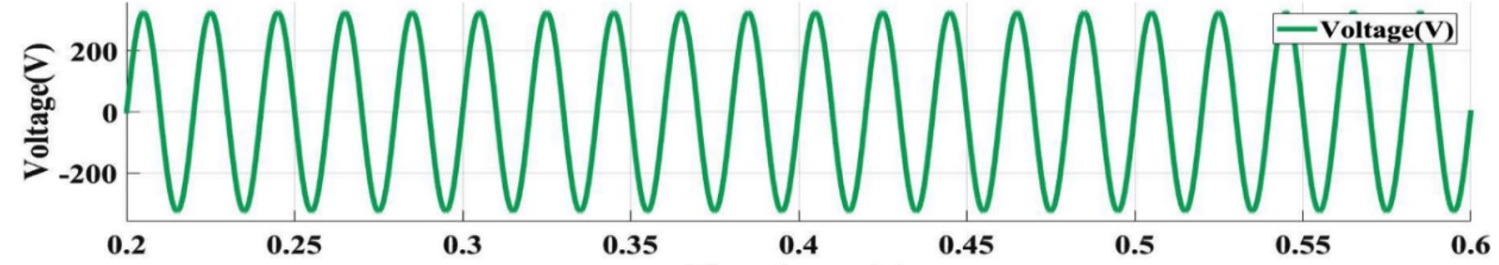

Time (seconds)

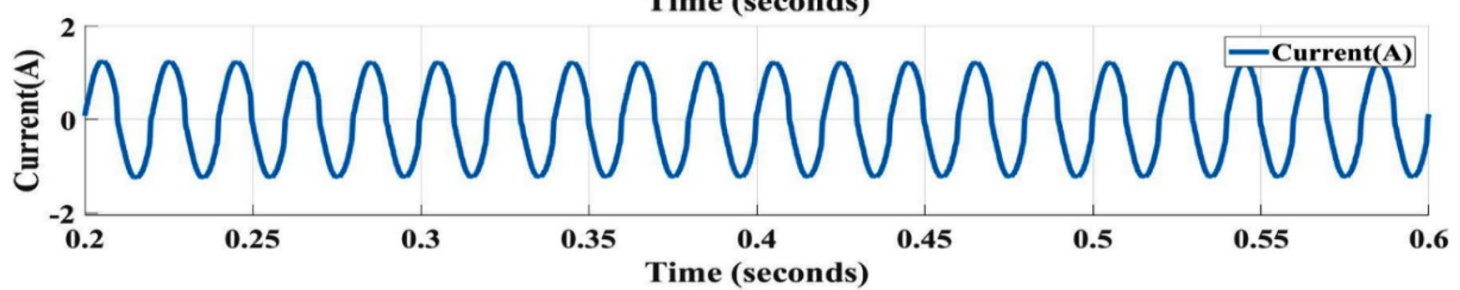

Fig. 6 Grid voltage and current waveforms

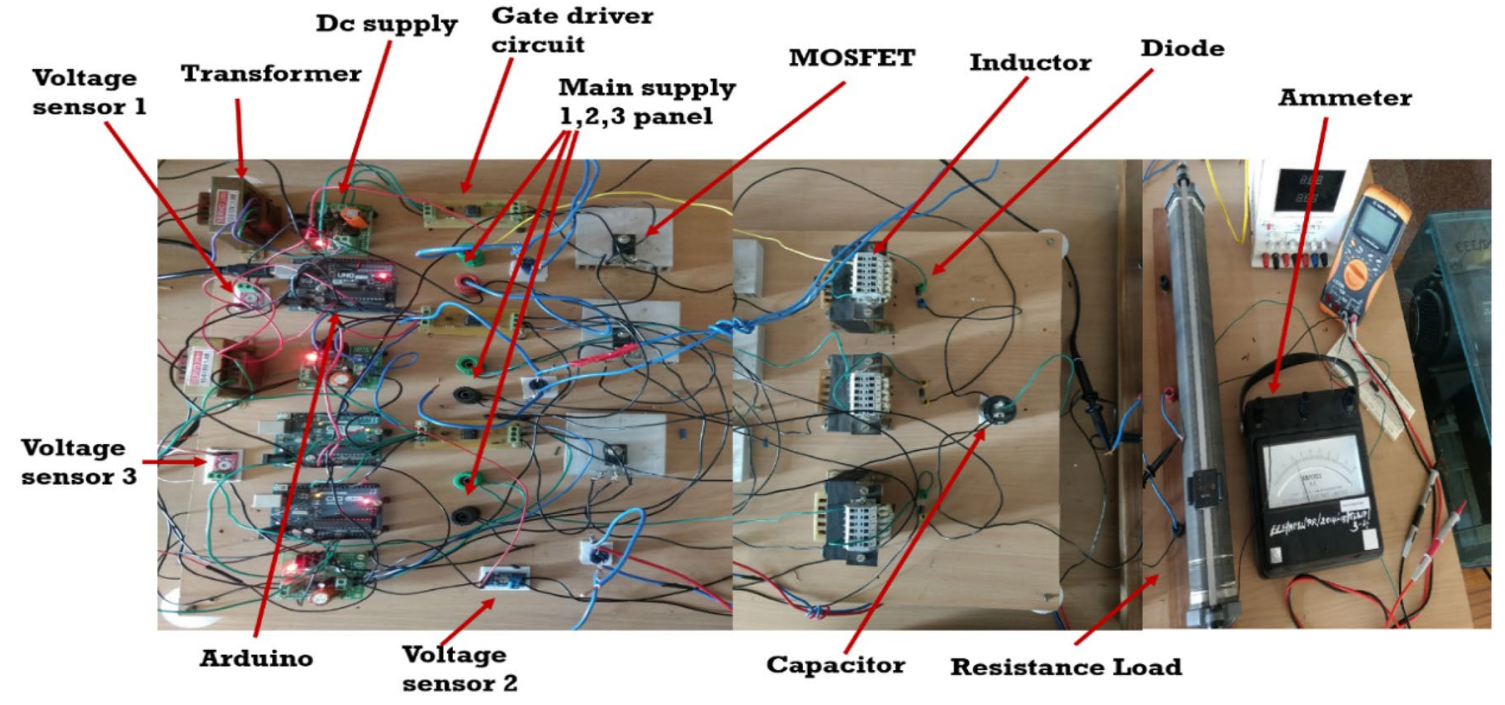

Fig. 7 Hardware implemented model of DC optimizer

As in Fig. 9, the gate driver circuit that accepts a lowpower input from the digital controller which is produces amplified PWM pulses to trigger the power these switches that have gate driver IC, HCPL3101 which offers isolation and amplification used for high-frequency operations. Further, to measure panel Voltage Arduino voltage sensor which is rated for $\mathrm{V}_{\mathrm{cc}}<25 \mathrm{~V}$ used for sensing the panel voltage and controlled to get the duty ratio for trigger the
MOSFET switch. Whereas, MOSFET (IRFP250N) with Heat sink is used for three individual DC-DC converters. In the proposed system a heat sink has been designed in order to maximize the surface area which is in contact with the surrounding cooling medium like air. The main factors which affect the performance of this heat sink are a choice of material, protrusion design, surface treatment, and Air velocity. 


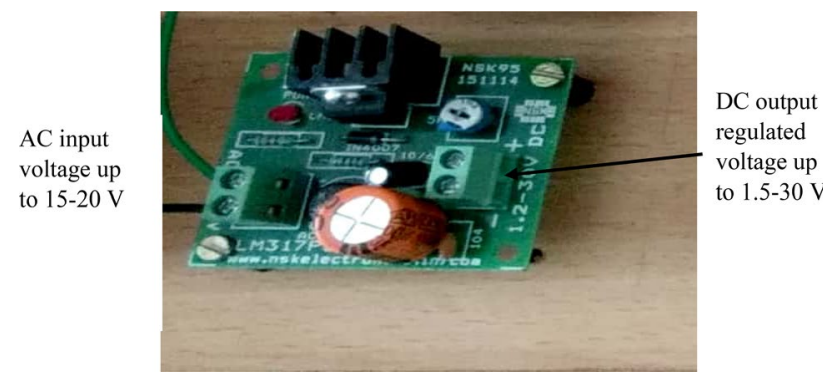

Fig. 8 Adjustable voltage regulator

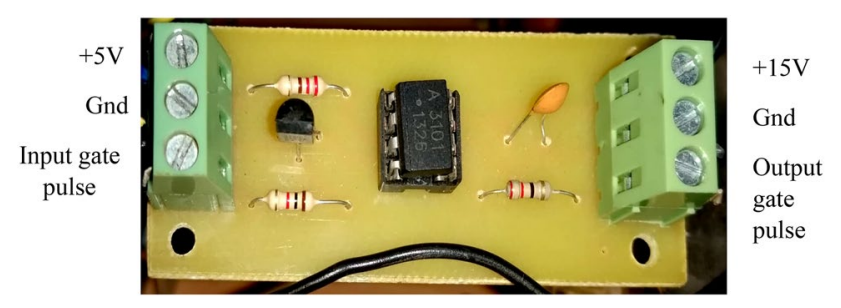

Fig. 9 Gate driver circuit

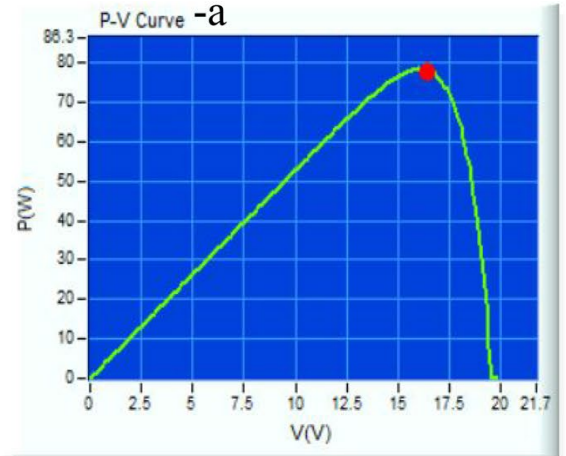

$\mathbf{a}$

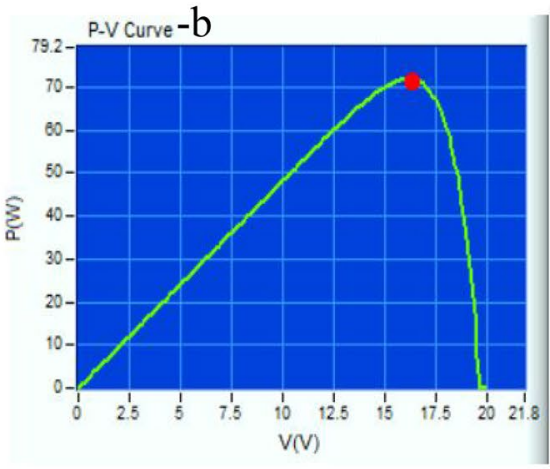

b inverter operates at near unity power factor. Furthermore, the grid current is almost free from harmonics.

\section{Conclusion}

A 240 Wp solar panel DC optimizer distributed system has been modeled and experimentally verified to deliver the maximum power to the single-phase grid. A novel PI controller based Fractional Open Circuit Voltage (FOCV) algorithm to extract the maximum power effectively with a reduction in the current sensor has been discussed. The PI Controller based Fractional Open Circuit Voltage is tuned by the simple Ziegler Nichols method. The simulation and experimental results show that the overall system can operate at any environmental conditions. The maximum power point settles fast and this method avoids the current sensors used in the conventional MPPT method thus reducing the overall cost of DC optimizer based distributed system. It is found that the proposed controller is robust against the different environmental conditions.

Fig. 10 a, b and c Solar -PV panels Operating points

To exercise the PI-based FOCV algorithm and control, the solar-PV characteristics with operating point inferred through the solar simulator display has been deployed for experimental analysis. Figures $10 \mathrm{a}-\mathrm{c}$ represent the operating points are in maximum power according to the environmental conditions of irradiation and temperature and are closely matched with simulation results.

The solar-PV voltage, current and duty cycle corresponding to given environmental conditions under $1000 \mathrm{~W} / \mathrm{m}^{2}$ at $35^{\circ} \mathrm{C}$ are shown in Fig. 11 . It shows the solar PV voltage and current are operating at their maximum points $\left(\mathrm{V}_{\mathrm{mp}}=16.7 \mathrm{~V}\right.$ and $\left.\mathrm{I}_{\mathrm{mp}}=4.56 \mathrm{~A}\right)$. Figure 12 depicts the grid voltage and current and shows that the

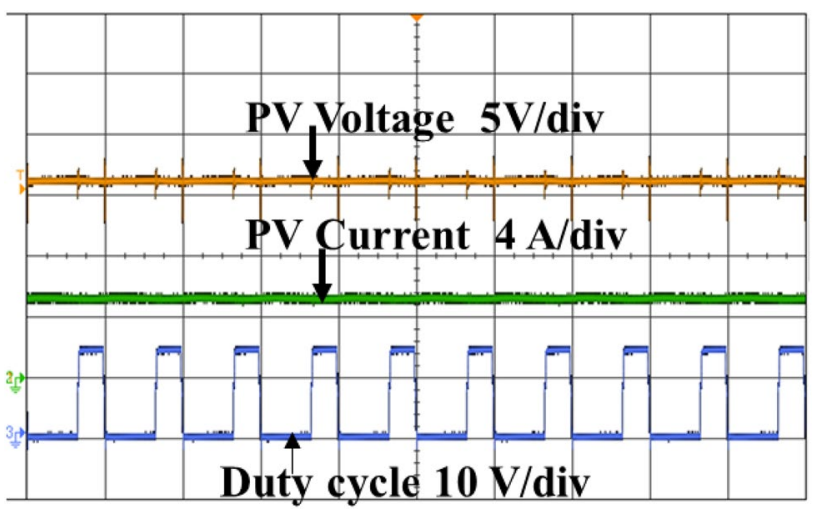

Fig. 11 Solar PV panel-1 Voltage, Current and duty cycle waveforms under $1000 \mathrm{~W} / \mathrm{m}^{2}$ at $35^{\circ} \mathrm{C}$

SN Applied Sciences 


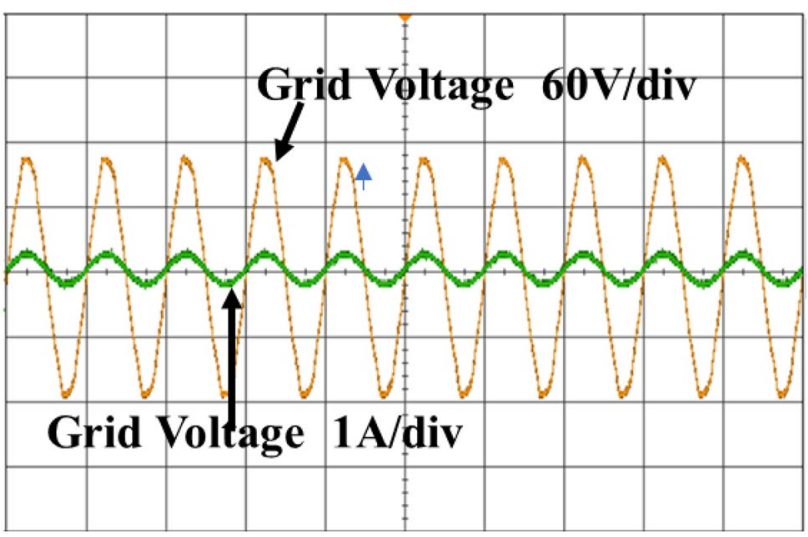

Fig. 12 Grid Voltage and current waveform

\section{Compliance with ethical standards}

Conflict of interest The authors declare that they have no conflict of interest.

\section{References}

1. Zahedi A (2006) Solar photovoltaic (PV) energy; latest developments in the building-integrated and hybrid PV systems. Renew Energy 31(5):711-718

2. Aquib M, Jain S, Agarwal V (2020) A time-based global maximum power point tracking technique for PV system. IEEE Trans Power Electr 35(1):393-402

3. Ghasemi MA, Ramyar A, Iman-Eini H (2018) MPPT algorithm for PV systems under partially shaded conditions by approximating I-V curve. IEEE Trans Ind Electron 65(5):3966-3975

4. Kan J, Wu Y, Tang Y, Xie S (2019) Flexible topology converter used in photovoltaic micro-inverter for higher weighted-efficiency. IET Power Electr 12(9):2361-2371

5. Qin S, Barth CB, Pilawa-Podgurski RCN (2016) Enhancing microinverter energy capture with submodule differential power processing. IEEE Trans Power Electron 31(5):3575-3585

6. Kim K, Krein P (2013) Hot spotting and second breakdown effects on the reverse I-V characteristics formono-crystalline $\mathrm{Si}$ photovoltaics. In: Proceedings of the IEEE Energy Conversion Congress and Exposition, pp 1007-1014

7. Kim KA, Krein PT, Seo G-S, Cho B-H (2013) Photovoltaic ac parameter characterization for dynamic partial shading and hot spot detection. In: Proceedings of the IEEE 28th annual applied power electronics conference and exposition, pp 109-115

8. Kim N, Parkhideh B (2018) Comparative analysis of non-isolated and isolated type partial-power optimizers for PV-battery series inverter architecture. In: 2018 IEEE energy conversion congress and exposition (ECCE), Portland, OR, 2018, pp 6207-6213
9. de Souza Silva JL, Moreira HS, de Mesquita DB, Cavalcante MM, Villalva MG (2019) Modular architecture with power optimizers for photovoltaic systems. In: 2019 International conference on smart energy systems and technologies (SEST), Porto, Portugal, 2019, pp 1-6

10. Kim N, Parkhideh B (2019) PV-battery series inverter architecture: a solar inverter for seamless battery integration with partial-power DC-DC optimizer. IEEE Trans Energy Convers 34(1):478-485

11. Zhang $X$, Chen M, Fu Y, Li Y (218) A step-down partial power optimizer structure for photovoltaic series-connected power optimizer system. In: 2018 IEEE international power electronics and application conference and exposition (PEAC), Shenzhen, 2018, pp 1-4

12. Zhu Y, Wu J, Wang R, Lin Z, He X (2019) embedding power line communication in photovoltaic optimizer by modulating data in power control loop. IEEE Trans Industr Electron 66(5):3948-3958

13. Deline C, MacAlpine S (2013) Use conditions and efficiency measurements of DC power optimizers for photovoltaic systems. In: 2013 IEEE energy conversion congress and exposition, Denver, CO, pp 4801-4807

14. Jena PK, Mohapatra A, and Choudhary P (2016) Comparative study of solar PV MPPT by perturbation and observation and fuzzy method. In: 2016 IEEE Uttar Pradesh section international conference on electrical, computer and electronics engineering (UPCON), Varanasi, 2016, pp 515-518

15. Elgendy MA, Zahawi B, Atkinson DJ (2012) Evaluation of perturb and observe MPPT algorithm implementation techniques. In: 6th IET international conference on power electronics, machines and drives (PEMD 2012), Bristol, pp 1-6

16. Rehman MdW, Bathina C, Karthikeyan V, Prashanth R (2016) Comparative analysis of developed incremental conductance (IC) and perturb and observe(P\&O) MPPT algorithm for photovoltaic applications. In: 2016 10th international conference on intelligent systems and control (ISCO) Year, pp 1-6

17. Lopez-Lapena O, Penella MT (2012) Low-power FOCV MPPT controller with automatic adjustment of the sample and hold. Electr Lett 48(20):1301-1303

18. Ostrowski M (2018) An adaptative OCV and SCC-based maximum power point tracking method for photovoltaic panels in the partial shading conditions. In: 2018 IEEE international conference on environment and electrical engineering and 2018 IEEE industrial and commercial power systems Europe (EEEIC/ I\&CPS Europe), Palermo, 2018, pp 1-6

19. Roman $E$, Alonso R, Ibanez $P$, Elorduizapatarietxe $S$, Goitia D (2006) Intelligent PV module for grid-connected PV systems. IEEE Trans Ind Electr 53(4):1066-1073

20. Sajadian S, Ahmadi R (2017) Distributed maximum power point tracking using model predictive control for photovoltaic energy harvesting architectures based on cascaded power optimizers. IEEE J Photovolt 7(3):849-857

Publisher's Note Springer Nature remains neutral with regard to jurisdictional claims in published maps and institutional affiliations. 